\title{
Entre renúncies, temors i deures. Anàlisi de l'estructura motivacional del consum ecològic
}

\author{
Marc Barbeta Viñas \\ Universitat Autònoma de Barcelona. Departament de Sociologia \\ marc.barbeta@gmail.com
}

Recepció: 03-10-2013

Acceptació: 13-05-2014

\section{Resum}

Segons algunes informacions, el consum ecològic ha experimentat, en els darrers anys, un augment notable entre alguns sectors de la societat. Tanmateix, les dades quantitatives de què disposem, tal vegada no són prou adequades per determinar a què es refereixen les persones quan parlen de consum ecològic (més enllà de les definicions oficials), ni tampoc per comprendre què els empeny a comprar aquest tipus de productes. Amb el present treball, es pretén donar resposta a aquests interrogants a partir d'una proposta d'anàlisi sociomotivacional i d'un enfocament qualitatiu, amb l'aplicació de les tècniques del grup de discussió i l'entrevista oberta. L'objectiu fonamental és configurar l'estructura motivacional bàsica del consum ecològic, en la mesura que té la capacitat de revelar els distints processos motivacionals que regulen la imatge del que és ecològic i el seu consum. Constatem que, atenent que els productes ecològics es configuren com un símbol significativament $\mathrm{i}$ afectivament sobrecarregat, el fet d'adquirir-ne s'afirma com un fenomen particular i, en alguns aspectes, diferencial, dins de les formes de consum que predominen avui dia.

Paraules clau: consum ecològic; procés motivacional; anàlisi qualitativa; marques.

\section{Abstract. Among sacrifices, fears and responsibilities: Analysis of the motivational structure of ecological consumption}

According to some data sources, ecological consumption in recent years has experienced a notable increase among some sectors of society. However, quantitative data are perhaps not sufficiently adequate to determine what consumers refer to when they talk about ecological consumption (beyond the official definitions) or to understand why consumers of ecological products want this type of consumption. The aim of the present study is to answer these questions by means of a certain socio-motivational analysis and a qualitative approach with focus group and interview techniques. The objective is to set the basic motivational structure of ecological consumption, as this has the ability to reveal different motivational processes that govern the image of what ecology and consumption is. We find that insofar as ecological consumption is a significantly and emotionally overloaded symbol, it affirms that it is a particular phenomenon and in some aspects differential within the predominant forms of contemporary consumption.

Keywords: ecological consumption; motivational process; qualitative analysis; brand. 


\title{
Sumari
}

\author{
1. Introducció i objectius \\ 3. Metodologia i disseny \\ 2. Sociologia motivacional: eficàcia \\ 4. Anàlisi i interpretació \\ simbòlica i sobredeterminació \\ motivacional \\ 5. Conclusions \\ Referències bibliogràfiques
}

\section{Introducció i objectius}

Diversos estudis recents constaten un augment notable del denominat «consum ecològic», molt en particular, entre determinats sectors socials de la població catalana ${ }^{1}$. Tanmateix, els estudis de caràcter quantitatiu ens diuen poc sobre la imatge que els consumidors tenen d'aquest tipus de productes i sobre els processos que els impulsen a adquirir-ne. Per a la metodologia en ciències socials, ja són un tòpic els problemes derivats de l'aplicació de mètodes quantitatius sobre objectes d'estudi caracteritzats per una certa densitat social i simbòlica, així com mediats per la subjectivitat dels actors implicats. Per això, mitjançant el present treball, ens proposem realitzar una aproximació qualitativa al fenomen del consum ecològic, en el que seria una primera i limitada exploració. Entenent-lo com un tipus particular de consum de marca, en aquest cas, la «metamarca ecològica», es persegueix l'objectiu de determinar-ne l'estructura motivacional, atenent les dimensions estructural i genètica, la qual cosa comporta explorar les imatges simbòliques, les representacions ideològiques i les actituds dels consumidors davant del consum ecològic, així com desentranyarne les lògiques genètiques subjacents.

En primer lloc, es presenta el plantejament teoricometodològic del treball, seguit d'un apartat on s'exposa el disseny de la investigació i el mètode d'anàlisi; a continuació, es presenten alguns dels resultats més rellevants de la investigació empírica, i, finalment, un apartat de conclusions i la bibliografia ${ }^{2}$.

\section{Sociologia motivacional: eficàcia simbòlica i sobredeterminació motivacional}

Trobem l'origen de la sociologia motivacional en els primers treballs del sociòleg Jesús Ibánez (1969). Aquest enfocament se situaria en l'àmbit genèric de l'estudi del comportament dels consumidors. La seva especificitat estaria

1. Vegeu, per exemple: Centre d'Estudis d'Opinió (2009, 2010, 2012); Federació de Cooperatives de Consumidors i Usuaris de Catalunya (2010), i Tendero (2011).

2. El mes de juliol de 2013, es va presentar una primera versió d'aquest treball dins del marc del XI Congreso de Sociología de la FES, celebrat a la Universitat Complutense de Madrid. Així mateix, constitueix una part d'una investigació més àmplia que va ser presentada com a tesi doctoral del mateix autor. D’altra banda, vull agrair a la María Jesús Izquierdo els comentaris que de ben segur han fet millorar el present treball. 
inscrita en l'intent de comprensió i interpretació dels mòbils, els valors i/o les normes que orienten i que configuren les imatges i les conductes de consum. La preocupació pròpia d'aquesta perspectiva seria la de respondre els perquès i el com de determinades conductes de consum (Gerth i Wright Mills, 1984: 121). L'aplicació que en fem per a la present proposta s'orienta cap a l'anàlisi de les formes d'estructuració de la demanda de la metamarca ecològica: el procés de configuració del desig de consumir, que es pressuposa el moment previ als actes de compra.

Entenent, com fa Callejo (1994), l'aspecte motivacional com un procés en el temps, es nega la perspectiva de "fet» que funciona com a causa - ja sigui una o més d'una-, per considerar la dimensió de procés motivacional. En aquest sentit, Ibáñez (1969: 86) assenyalava que, en l'anàlisi del procés motivacional, "no se trata de buscar un factor que pone en marcha el comportamiento - la causa-, sino la lógica interior de todo proceso de comportamiento". Lògica que, com adverteix Ortí (1979: 9), respon a l'orientació afectiva subjacent a la dinàmica de la conducta del consumidor en una situació social concreta. En l'anàlisi sociomotivacional, s'hi pressuposa un subjecte: el consumidor com a ésser social (Callejo, 1994: 108). Així, les «voluntats sentides» per aquest subjecte s'enfoquen com a processos d'interiorització dinàmica d'elements i d'esquemes afectius i relacionals configurats de manera social i biogràfica. Els desigs com a voluntat d'expressió no són tan sols l'elaboració psíquica de les pulsions corporals, sinó també l'elaboració idiosincràtica de l'entorn social, especialment de les relacions primàries amb els altres (Izquierdo, 1996: 168). Quan parlem de «voluntat», del que es tracta és de com «[...] las disposiciones interiores, la interiorización de la exterioridad, permiten a las fuerzas exteriores ejercerse, pero según la lógica específica de los organismos en que están incorporadas» (Bourdieu, 1980: 95).

Aquí situem els processos motivacionals de consum en un nivell pròpiament psicosocial, allunyat de les visions més «psicologistes», que enfoquen tan sols factors d'ordre individual. És per això que, com veurem, entre els models teòrics que han rebut més projecció en les investigacions de consum, la sociologia motivacional troba els seus fonaments, principalment, en el model psicoanalític i en el geneticoestructural, tal com els exposa Callejo (1994). Desconsiderem, en canvi, les aproximacions reflexològiques i (únicament) semiològiques, en la mesura que no ofereixen marcs per abordar els fenòmens de consum des de l'àmbit social.

En un treball monumental, Ortí (1994) desenvolupa, a nivell formal, els elements estructurants dels processos de demanda pels quals tot procés motivacional d'una marca-producte estaria més o menys condicionat. Destaquem, en primer lloc, el valor d'ús de tot producte, la qual cosa respondria al seu nivell funcional i que, en la pràctica del consum, acostuma a semantitzar-se (De Lucas, 1988: 20). En segon lloc, el nivell simbòlic, que tendeix a estar travessat per un nivell social i per un d'estrictament personal. El primer es compon d'elements cognitius que configuren un sistema de significats que promouen determinades articulacions semàntiques associades amb la marca-producte $\mathrm{i}$ 
amb el consum que se'n fa: les imatges que presenta, les representacions que evoca o que connota, les actituds que encarna per part dels consumidors d'uns grups socials determinats, etc. El segon es refereix a la transferència afectiva o valorativa amb la qual el consumidor — a nivell analític personal- viu els elements socioculturals i simbòlics anteriors, assumint-los com a propis o, per contra, rebutjant-los ${ }^{3}$.

La centralitat dels valors simbòlics en l'esquema d'Ortí situa el concepte d'eficàcia simbòlica en un espai estratègic per realitzar l'anàlisi motivacional. En la seva aplicació en el camp del consum, definiria els efectes que una marca-producte exerceix sobre la seva demanda (actual o potencial) en tant que objecte de consum, la qual cosa hi provocaria, des d'una perspectiva motivacional, una certa fixació o un lligam dels consumidors (Barbeta, 2014b). Així, es donaria, a les marques o al producte, l'estatut de simbols, en el sentit que haurien postulat la perspectiva cognitivoafectiva del simbolisme desenvolupada per autors com ara Ricoeur (1975), Malrieu (1971) o Lorenzer (1970). Des d'aquesta concepció, s'entendria que els significats dels símbols se situen més enllà de la realitat lingüística i impliquen una càrrega afectiva. No només estarien mediats per interessos o valors socials, sinó també pels desigs (més o menys conscients) que busquen realitzar-se en la cultura.

A partir d'aquest model, podem afirmar que tota imatge de marca condensa un conjunt de processos, atributs i característiques més o menys àmplies en funció del context de mercat i del moment sociohistòric en què s'inscriu, la qual cosa implicaria que tota marca-producte té la capacitat d'evocar una pluralitat de sentits, significacions i, inclús, posicions emocionals en els consumidors. L'eficàcia de la metamarca ecològica es produiria quan aquesta fos capaç d'estructurar, en un sector del mercat, una imatge amb valors simbòlics, representacions, actituds i/o hàbits de consum que, al mateix temps, evocarien, en els consumidors d'aquest sector social, el seu desig, interès o disposició a consumir-ne. De manera que l'eficàcia trobaria el seu "poder motivador» en l'adequació de l'estructura simbòlica de la imatge de la marca-producte en determinats contextos socials i personals, és a dir, la seva ubicació coherent dins de l'univers simbòlic dels consumidors, com a forma de resolució simbòlica o imaginària de determinats conflictes i/o processos associats al consum de la marca o del producte (Ortí, 1987: 69).

El treball d'anàlisi dels processos sociomotivacionals de consum consistiria, així, a determinar l'articulació dels elements associats a una marca, amb el conjunt de lògiques motivacionals (components dinàmics) subjacents que fan efectiva l'eficàcia simbòlica de les marques o dels productes. Les relacions entre elements i lògiques s'entenen com a relacions de sobredeterminació (Callejo, 1994: 100), amb l'existència d'una certa variabilitat en la mobilització d'unes o d'altres en cada procés motivacional concret, determinat, a la vegada, per la

3. Els dos nivells dels símbols es corresponen amb les dimensions informacional i energètica de l'eficàcia simbòlica d'Ortí (1994: 61), en una reinterpretació i reelaboració de la concepció lévi-straussiana originaria. 
marca-producte en qüestió (ubicació en el mercat, en el sistema de marques, etc.) i per la capacitat d'aquesta de posar en joc les característiques psicosocials i contextuals dels consumidors.

Els elements associats a les marques es poden inscriure dins de l'anomenada "cultura de consum», en tant que conjunt de valors, representacions, hàbits $\mathrm{i}$ creences associades a la imatge de marca $\mathrm{i}$ al fet de consumir. La pràctica del consum implica reproduir formes culturals específiques i significatives de vida amb les quals es comuniquen i es defineixen identitats socials, i que també serveixen per generar relacions amb els altres (Slater, 1997: 4). Destaquem, seguint Marinas (2012: $37 \mathrm{i}$ s.), tres plans que componen la cultura de consum i que utilitzarem de pauta per analitzar els elements bàsics dels processos motivacionals: el saber fer (pràctiques, usos, hàbits, codis, etnomètodes, etc.); les representacions ideologiques ${ }^{4}$ (imatges, signes, símbols, mites, etc.), i la identitat (rituals de pas, identificacions).

Pel que fa a les lògiques, el nivell personal i afectiu es correspondria amb el nivell de la simbolització transferencial implicada en els processos motivacionals de consum (Ortí, 1994). La teoria psicoanalítica de la personalitat, concretament la qüestió dels tipus libidinals i els models ideals elaborats per Freud (1905, 1933), Klein (1946) i altres autors, generalment, s'ha utilitzat per abordar els components afectius o emocionals dels processos de consum, els quals se'ls considera orientats per un desig més o menys conscient, o inclús inconscient (Ortí, 1979). Amb certa proximitat amb la teoria psicoanalítica de les relacions d'objecte, des de la sociologia, s'han realitzat intents realistes i fecunds de «sociologització» de les categories aportades per la psicoanàlisi. En aquest sentit, Ortí (1998) denomina «tipus sociolibidinals» el desenvolupament de certes estructures caracterials en el marc de determinats contextos socials. Aquestes estructures consistirien en les formes de subjectivació concreta de les relacions amb determinats objectes (com ara una marca, etc.), ateses unes formacions ideològiques i culturals desenvolupades en el context d'una posició social objectiva ${ }^{5}$. Això no obstant, com el mateix Ortí assenyala (1986: 214), en l'anàlisi sociomotivacional, es tracta d'analitzar les coordenades motivacionals psíquiques, culturals i de classe, més que no pas les característiques individuals dels consumidors.

En segon lloc, s'ha tendit a projectar la lògica socioestructural implicada en els processos motivacionals de consum per tal de referir-se, primer, a

4. Seguim una concepció àmplia i multidimensional del concepte d'ideologia, desenvolupat per autors com ara Therborn (1980) com a dispositiu mitjançant el qual els subjectes signifiquen els processos socials, la seva realitat i la dels altres.

5. En la qüestió dels tipus libidinals o les estructures de caràcter, s'ha tendit a destacar el paper que tenen les estructures psíquiques, les fases i les posicions en el procés d'evolució libidinal i agressiu dels individus, així com les formacions d'ideals. Des de la proposta sociolibidinal, es tractaria d'enfocar els elements afectius, els desigs i els conflictes subjacents en els diferents tipus de relació amb les marques o els objectes de consum. És a dir, la manera socialment modelada de realitzar o de resoldre aitals desigs o conflictes afectius, amb el medi social $\mathrm{i}$ les formacions culturals i ideològiques com a condicionants de les dinàmiques afectives viscudes. 
l'articulació dels estils de vida i a les identitats amb les posicions socials dels consumidors: les connexions entre els diversos contextos socials en què aquests s'inscriuen i des dels quals configuren els marcs de sentit des d'on consumeixen (Alonso, 2005: 99). Segon, per abordar les estratègies que consumidors i grups socials desenvolupen en el consum (Bourdieu, 1980). Estratègies que respondrien al "para qué se usa el consumo" (Callejo, 1995: 89), en referència a les expectatives, les aspiracions vitals i les projeccions d'allò que es pretén realitzar en o a través del consum, considerant l'estructura social i el sistema d'imatges de marca, en el cas que ens ocupa, com els referents o els camps d'operacions fonamentals. Des de la sociologia del consum, diferents treballs han posat de manifest els tipus d'estratègies bàsiques que desenvolupen els consumidors en les relacions de consum. Autors com ara Veblen (1899), Simmel (1911) o el mateix Bourdieu (1979) han posat l'accent en les estratègies de diferenciació vertical i d'imitació a través del consum; mentre que Hebdidge (1979), Miller (1987), Grignon i Passeron (1992) o Chaney (1996) s'han fixat en les estratègies de diferenciació en un sentit més horitzontal i en els processos d'identificació com a formació de grups de pertinença. Aquí, les formacions culturals, els estils de vida i de consum constituirien mitjans d'expressió i de reconeixement de determinats grups socials, més enllà de la referència única als grups situats al cim de l'estructura social.

\section{Metodologia i disseny}

L'enfocament metodològic adoptat ha estat qualitatiu (o estructural). S'han creat dos grups de discussió (GD) i s'han realitzat nou entrevistes obertes (EO). L'objectiu perseguit ha estat l'anàlisi de determinades "posicions estructurals», entenent que aquestes organitzen l'entramat social i discursiu dins del camp d'estudi concret (Castro Nogueira i Castro Nogueira, 2001: 178). Per la configuració de la mostra, s'han pres com a referència algunes de les dades quantitatives existents sobre el consum ecològic al Principat de Catalunya. Aquestes dades ens proporcionen informació relativa al perfil predominant del consumidor ecològic, sobre el qual es projecta el disseny.

Les variables i els criteris considerats, d'acord amb el paper diversificant que tenen (Ibáñez, 1979), han estat ${ }^{6}$ : la classe social (per posició socioeconòmica); el sexe, l'edat i el cicle vital (en funció de les responsabilitats familiars); el nivell d'estudis, l'hàbitat i l'espai de compra predominant (cooperatives de con-

6. A manera de caràcters categorials, hem establert criteris que assegurin un cert grau de continuïtat en la pràctica del consum ecològic entre els consumidors de la mostra: una compra mínima setmanal de productes ecològics i la (co)responsabilització de la compra a la llar on viuen. D'altra banda, per realitzar el reclutament de consumidors, sempre s'han utilitzat xarxes relacionals pròpies, excepte al GD2, que s'ha fet mitjançant l'empresa InfuLab d'Aplus+. Hi afegim que un dels límits més destacables de la mostra és l'absència de consumidors de les classes mitjanes-baixes, que, això no obstant, són minoritàries entre els consumidors ecològics. El treball de camp s'ha desenvolupat entre finals de l'any $2010 \mathrm{i}$ al llarg de 2011. 
Taula 1. Perfil del consumidor ecològic al Principat de Catalunya

\begin{tabular}{rlll}
\hline \multicolumn{1}{c}{ Sexe: } & \multicolumn{1}{c}{ Edat: } & \multicolumn{1}{c}{ Classe social: } & \multicolumn{1}{c}{ Nivell d'estudis: } \\
\hline Dona: $49,8 \%$ & 16 a 34: $28,3 \%$ & Mitjana-alta: $42,7 \%$ & Universitaris: $36,1 \%$ \\
Home: $50,2 \%$ & 35 a $49: 35 \%$ & Mitjana: $40,8 \%$ & Secundaris: 39,6 \\
& 50 a $64: 22,7 \%$ & Mitjana-baixa: $16,5 \%$ & Primaris: $23,1 \%$ \\
& Més de $65: 14,0 \%$ & & Sense estudis: $0,8 \%$ \\
\hline
\end{tabular}

Font: elaboració pròpia a partir de dades del baròmetre de consum de productes ecològics, 2010.

Figura 1. Esquema del disseny tècnic final

Eix de la posició socioeconòmica

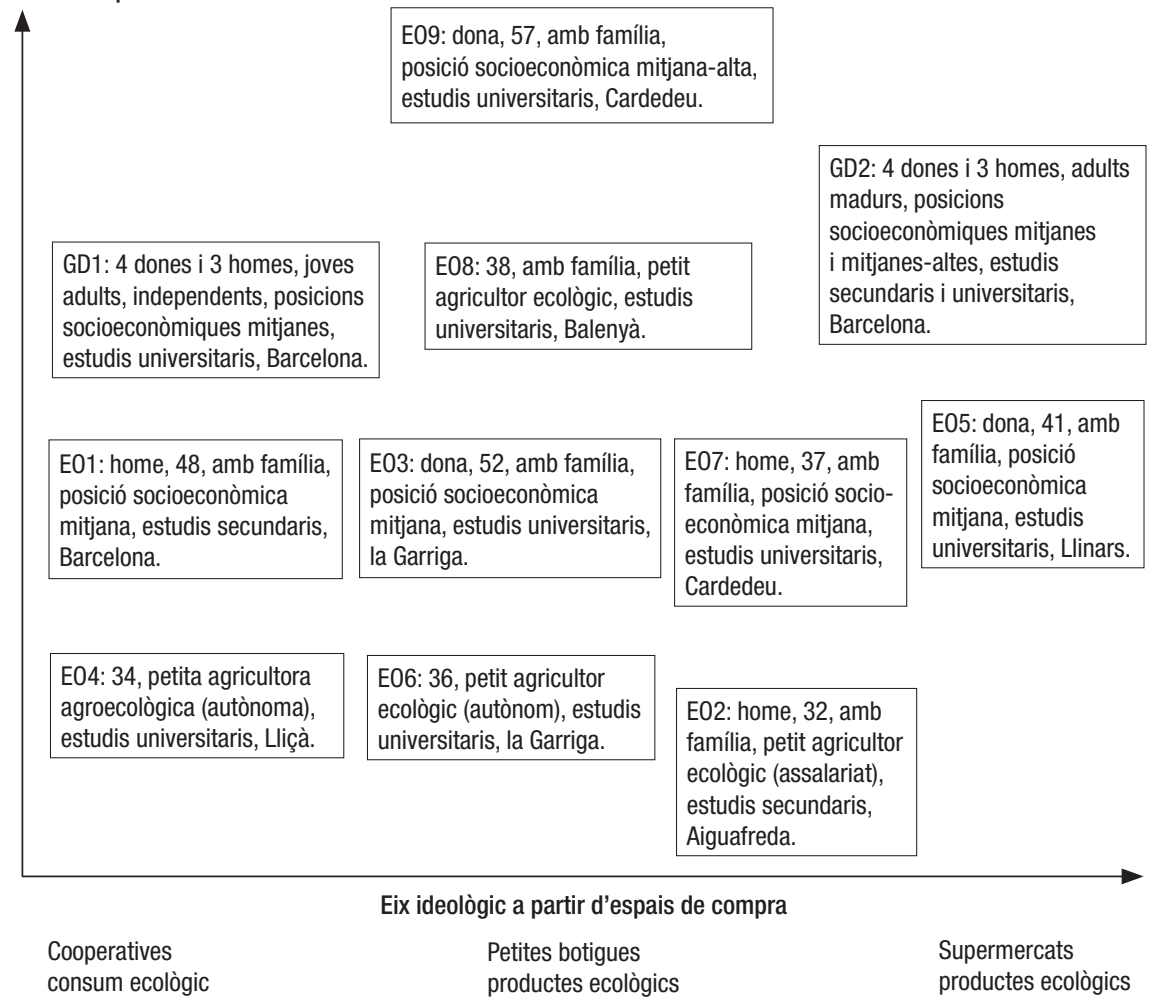

Font: elaboració pròpia.

sum ecològic, petites botigues de productes ecològics, grans superfícies de productes ecològics). Respecte a la confecció dels grups i a l'elecció d'entrevistats, dins de l'homogeneïtat social necessària per a la productivitat discursiva, s'hi han incorporat elements d'heterogeneïtat, per tal de captar els criteris diferencials de l'estructura discursiva. En referència a la representació dels sectors socials predominants, s'hi han incorporat les posicions socioeconòmiques 
mitjanes-altes i mitjanes, i amb nivells d'estudis superiors i mitjans. Pel que fa al sexe, les dades quantitatives reclamen la mateixa presència d'homes que de dones en les dinàmiques ${ }^{7}$. En relació amb el cicle vital, mantenim la hipòtesi de possibles diferències discursives entre consumidors amb responsabilitats familiars i sense, d'aquí que s'hagin configurat dos GD diferenciats en aquest sentit. S'hi inclouen també consumidors d'entorns urbans i semirurals, per tal de captar-ne les possibles variacions discursives. Amb la variable espai de compra, s'ha configurat una hipòtesi orientada a la configuració dels grups i de les entrevistes, entenent que és un dels factors que "trenca el camp» amb més força (Knodel, 1993), és a dir, a partir dels espais de compra predominants dels consumidors, podríem esperar orientacions ideològiques i motivacionals al consum més o menys distintes.

Tant per la manera d'emprar les pràctiques qualitatives, com per l'aproximació a l'anàlisi dels discursos, aquest treball s'inspira en el corrent denominat Escola de Qualitativisme Crític de Madrid, representada, entre d'altres, pels treballs d'Ibáñez (1979), Ortí (1986), Alonso (1998) i Conde (2009). S'ha desenvolupat una proposta d'anàlisi pragmàtica dels discursos, vinculada a la investigació dels sentits contextualitzats socialment del fenomen que s'estudia, en el marc d'una concepció sociohermenèutica de l'anàlisi qualitativa (Alonso, 1998). Hem seguit, en aquesta línia, la denominada «anàlisi sociològica del sistema de discursos» (ASSD) (Conde, 2009).

L'anàlisi ha consistit en el desenvolupament d'una modelització analítica de l'estructura motivacional del consum ecològic, atenent la varietat de processos motivacionals que la conformen. Com a procediment guia d'anàlisi, s'ha seguit la determinació de les posicions motivacionals mitjançant la situació de les varietats empíriques de les parles dels consumidors en un model de posicions arquetípiques (Conde, 2009: 150 i s.; Alonso, 1998: 214). L'anàlisi de les configuracions narratives, així com dels espais semàntics, procediments bàsics del mètode que representa l'ASSD ${ }^{8}$, han servit per configurar les posicions, i també per analitzar-ne el desenvolupament discursiu. Les posicions es configuren a partir de les imatges i de les actituds dels consumidors davant de la marca i del consum que en fan, de manera que s'hi condensen perspectives i orientacions motivacionals bàsiques. Entre posicions, les diferències s'estableixen per la variabilitat en les orientacions, com també per l'ordenació i la rellevància

7. Les diferències discursives entre homes i dones, si són difícilment identificables en els grups de caràcter mixt, es buscaran mitjançant les entrevistes.

8. Les configuracions narratives constitueixen els eixos o vectors multidimensionals que estructuren els discursos i n'expressen el codi. Es corresponen amb l'anàlisi de la funció metalingüística del text. Alguns autors relacionen aquesta dimensió amb les sinalàxies heraclitianes, que postulen parelles contraposades que es defineixen recíprocament. Com a procediment d'anàlisi, permet estructurar el text des d'una certa coherència interna i relacionar-ne el sentit amb els contextos de producció. Els espais semàntics defineixen el conjunt de termes sistematitzats per similitud, contrast, proximitat i jerarquització, aspectes que donen als fets sentits diferenciats i que pressuposen una competència social determinada. Són útils per establir els camps de significacions i associacions en relació amb l'objecte d'estudi (vegeu Alonso, 1998; Conde, 2009). 
motivacional que tenen. Cada posició es correspon amb un procés motivacional específic i diferencial respecte als altres, en què l'eficàcia simbòlica de la metamarca ecològica mobilitza elements i lògiques motivacionals concretes.

\section{Anàlisi i interpretació}

\subsection{Les posicions motivacionals bàsiques en el consum ecològic}

Per a la configuració de les posicions motivacionals, ja a partir del material empíric, hem partit d'una primera hipòtesi que estableix un triple vector multidimensional que estructura el corpus de textos produït pels consumidors en les dinàmiques. Cada vector defineix orientacions al consum i ho fa en un contínuum que marca polaritzacions ideals contraposades?.

- El vector de la salut, associat a una certa inquietud o preocupació dels consumidors per aquesta qüestió, així com els valors i les creences que se'n deriven, a més de la relació que hi manté el consum ecològic.

- El vector socioambiental, associat també a certes inquietuds i/o preocupacions relacionades amb el medi ambient $\mathrm{i}$ amb determinades problemàtiques socials, així com els valors i les creences que se'n deriven.

- El vector del vincle, que queda fora de consideració en aquest treball per raons d'espai i que ha estat desenvolupat a Barbeta (2014a).

Val a dir que, amb la finalitat de captar la diversitat de l'estructura motivacional del consum ecològic, no hem partit de cap preconcepte ni de cap definició sobre què és i què significa ecològic i el consum que se'n produeix. Hem deixat que siguin els consumidors qui desenvolupin i delimitin significativament l'objecte en el transcurs de les dinàmiques. Partir de representacions prèvies podria implicar un impediment important en la captació de la variabilitat estructural i discursiva del fenomen ${ }^{10}$.

La segona hipòtesi de la modelització, ja referent als discursos, estableix la configuració de tres posicions motivacionals bàsiques, amb nuclis discursius més o menys diferenciats. La seva relació amb els vectors respondria a la

9. L'exercici de la polarització s'adreça a l'estructuració bàsica del text a partir de vectors o d'eixos que constitueixen la «matriu» dels discursos des de la coherència interna que presenten.

10. Aquest plantejament ha implicat:

a) Que la categoria ecologica s'atribueixi a un ventall relativament ampli de productes, sempre en funció dels contextos discursius, i fins i tot que el concepte ecologgic no només s'atribueixi a productes, sinó també a pràctiques de consum. Tot i això, els productes alimentaris són els que han tingut més presència en els discursos.

b) Que siguin definits (i reivindicats) com a ecològics determinats productes sense segell ecològic, per tant, no considerats així des del punt de vista legal.

c) Una clara evidència que existeix un cert decalatge entre la definició legal i «oficial» dels productes ecològics i la imatge social que té entre els seus consumidors.

d) Condicionar el disseny de la mostra i, especialment, el plantejament de les dinàmiques de grups i entrevistes. 
Figura 2. Estructura motivacional bàsica del consum ecològic a partir de les posicions i dels vectors motivacionals

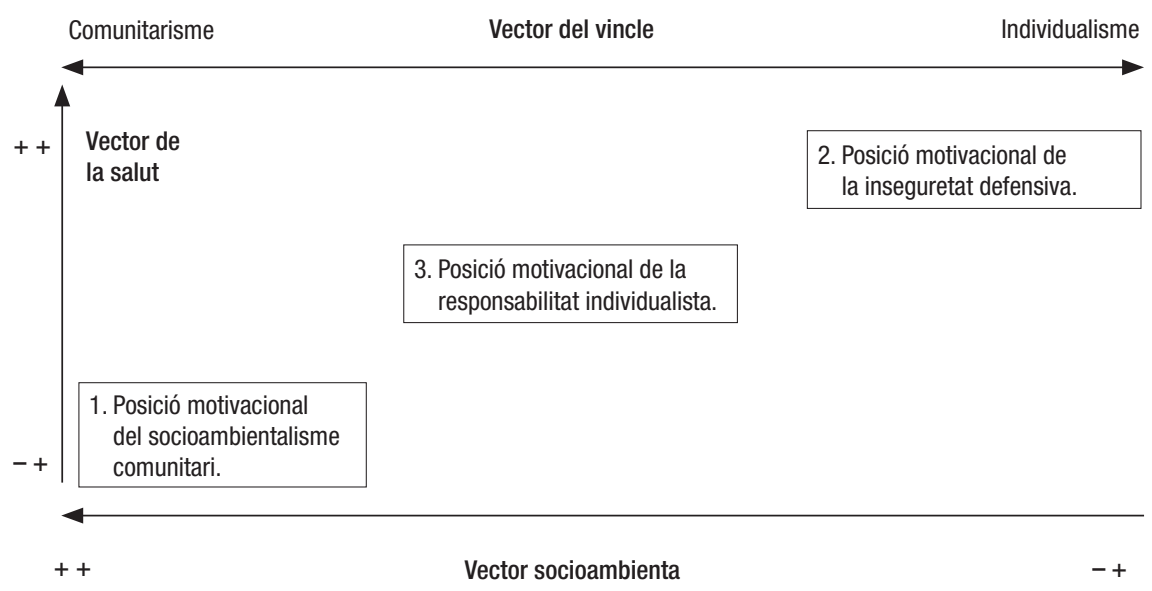

Font: elaboració pròpia.

«identificació», «assumpció» i/o "proximitat» amb ells, així com a les maneres específiques de desenvolupar-los. Les posicions ens proporcionen una certa coherència sobre la configuració de les imatges i les actituds dels consumidors davant del que és ecològic i del consum d'aquest tipus de productes, com també la relació amb els contextos socials allà on s'han produït. A la figura 2, hi mostrem les tres posicions motivacionals en el marc dels vectors definits. Als apartats següents, hi presentem alguns dels resultats més destacats relatius a cada posició.

\subsection{El consum ecològic com a renúncia al servei d'una «causa»: posició motivacional del socioambientalisme comunitari}

Sorgida del discurs predominant del GD1, l'EO1, l'EO4 i l'EO6, respondria al paradigma motivacional del consum ecològic orientat per la màxima valoració de les implicacions favorables d'aquest sobre el medi ambient i la transformació social en un sentit proper a l'«ecologisme» — com el defineix Riechmann (1994: 116)—, i explícitament oposat al «consumisme», en tant que sistema ideològic i model de consum dominant. En el desenvolupament discursiu, emergeix l'ideologema bàsic del consum ecològic al servei d'un canvi «ecosocial», quan aquest es concep i es defineix com un "procés» de "construcció d'alternatives» al servei de "nous models econòmics, socials i ambientals» (GD1, EO1, EO4). Les referències al consum ecològic es realitzen a través d'uns sintagmes més propis del combat ideològic que no pas d'una pràctica de consum, de manera que, fins i tot, queda resignificat com una forma de «lluita» 
(GD1). Es desplaça, així, l'espai semàntic del consum ecològic al terreny de la praxi política. Precisament, una de les característiques del present discurs és la de situar el consum ecològic en l'epicentre de les pràctiques d'alguns dels nous moviments socials, la qual cosa expressaria, seguint Miller (1987), un procés d'apropiació significativa de la imatge del consum ecològic, en la mesura que aquests consumidors cooperativistes la configurarien a nivell simbolicomotivacional, en un sentit "propi», en articulació amb determinats models politicoideològics, i orientant el consum a la transformació «ecosocial», que, almenys a nivell retoric, reivindiquen.

Aquesta posició ubicaria, de manera preeminent, el consum ecològic en un marc simbòlic universal i públic, des del qual se'n realitza una projecció social. Les problemàtiques socioeconòmiques $\mathrm{i}$ ambientals tenen una presència més que destacada dins l'univers de representacions ideològiques d'aquests consumidors, com a elements de legitimació i racionalització d'aquest tipus de consum. El discurs articula sintagmes de crítica i denúncia al model del «capitalisme imperant», al qual diuen que s'oposen i davant del qual el que és ecològic s'articula com una reacció socioambientalista. Sobre el capitalisme consumista, recau tota una càrrega afectiva en forma de protesta i de rebuig; la imatge del capitalisme i les conseqüències que comporta condensen una bona part dels problemes i dels conflictes que assetgen el món, i constitueix el blanc de les crítiques com a tòpic comú: el model que malbarata energia fent-ne un ús desproporcionat, basat en exportacions $i$ en importacions com a norma comercial, amb la contaminació consegüent; el model que destrueix el territori i que tan sols planteja un "creixement exponencial» per poder sobreviure (EO4) i que no es proposa reduir residus, reaprofitar recursos, etc. "L'ànim de lucre» se situa en el discurs en la base del capitalisme, i entre les conseqüències que comporta també s'hi poden comptar l'aillament, la injustícia social, la individualització i la pèrdua del que anomenen "xarxes socials», que, segons opinen els consumidors, esdevé cada vegada més present en determinats barris de ciutats com ara Barcelona. Es dibuixa, en definitiva, un model destinat al fracàs, que troba el màxim exponent en el consumisme nord-americà, que representa per aquests consumidors un model d' "anticonsum» (GD1). Expressions com aquesta revelen, en sentit latent, un espai simbòlic no consumista del que pot ser o del que ha de ser el consum, que és justament allà on tendeix a projectarse la imatge del consum ecològic des de la posició present.

Aquesta es configura en l'articulació d'un sistema de significats atribuïts sobre el que és ecològic, que gira al voltant de valors i de normes associats a un fort compromís social i medioambiental. La fonamentació eticopolítica dels valors del que és ecològic s'orienta a la gestió del que és possible i del bé comú; especialment els de contingut socioambiental són els de més rellevància, davant d'aquelles concepcions que "només» — diuen— atenen el control o la prohibició de pesticides, transgènics i additius diversos. Inclús es rebutgen aquestes visions «restringides» del consum ecològic per estar —afirmen insistentment - al servei de multinacionals que veuen un mercat creixent en aquest tipus de productes, especialment els alimentaris. Aquests consumidors es man- 
tenen crítics amb les definicions oficials, per la seva reglamentació insuficient, destinada només a "poder-hi posar l'etiqueta» (GD1), sense que això impliqui «contemplar aspectes socials» (EO4), «transformar les relacions injustes» (EO1), ni "contradir la lògica del capital» (GD1). Més aviat, suposa utilitzar «la marca» per reproduir-la. Des d'aquesta posició, el consum ecològic sense significació socioambiental perd tota justificació: «una persona que consumeix producte ecològic i se'n va al Veritas, per mi, no té cap mena de sentit» (GD1).

Analitzant el desenvolupament discursiu de la posició, observem com s'articula, en el procés motivacional, una dimensió ideal i imaginària, expressió de la màxima coherència ideològica dels valors socioambientals. En aquesta dimensió, la conducta dels consumidors s'orienta mitjançant una càrrega motivacional emanada de la figura de l'ideal del jo (Freud, 1933). L'ideal del jo socioambientalista constituiria la imatge que cada consumidor - a nivell personal - es proposa crear com a model de màxima coherència, i per la qual s'identifica amb els valors socioambientals projectats sobre el consum ecològic, amb la qual cosa pot orientar el sistema de preferències personals a favor d'aquest. En el discurs, s'hi observa aquest procés en el conflicte per la (in) coherència - de vegades, verbalitzat amb el mateix significant de coherènciaque va emergint en les dinàmiques com a problema associat a la identitat personal dels consumidors. Aquests exhibeixen formes i estils de vida associats a significacions socioambientals, com ara l'assumpció d'actituds de consum austeres, la realització de pràctiques de reciclatge, la compra en cooperatives de consum ecològic, etc.: "D: Som gent que vivim amb molt poc..." (EO4); «H: Sóc bastant auster...» (GD1).

Tot i això, afloren, al mateix temps, contradiccions més o menys latents, mitjançant les quals s'evidencia la incapacitat col-lectiva, majoritàriament manifestada per part de joves adults de classe mitjana amb capital cultural i formatiu elevat, de desprendre's de determinades «necessitats» — titllades per ells mateixos de "consumistes»—, com ara l'ús de mòbils, ordinadors, la valoració estètica de la roba i una estructura de gustos pròpia d'aquesta fracció de classe, segons Bourdieu (1979: 177) i Borràs (1998). Així mateix, és palesa la impossibilitat —al GD1 - d'arribar a un acord de mínims sobre el que és o ha de ser un «ús racional i sostenible» dels productes. Contradiccions viscudes també a nivell personal, per exemple, en la distància ideològica entre esferes distintes de vida («T"entra la contradicció [...] treballar en una agència de publicitat, de dir: "cony"...", EO1), o en la "debilitat» (contradictòria) de deixar-se guiar pel desig de consumir en botigues de marques de moda, com ara Mango o Zara (GD1). S'intenta justificar aquestes contradiccions a partir del consum ecològic en quantitat com a element compensador, o inclús amb l'argumentari —més contradictori encara - de la inevitabilitat de realitzar determinades pràctiques de consum en la societat en què viuen. Aquestes contradiccions, en definitiva, revelarien les dificultats del jo dels consumidors pel que fa a la mediació amb els desigs poc ecològics, així com amb la realitat externa mediada per les posicions de classe en què s'inscriuen. Es posaria en evidència, d'aquesta manera, el conflicte per la coherència o, el que és el mateix, les dificultats dels consumidors 
per complir amb l'ideal del jo socioambientalista. De tal manera que emergeix —especialment al GD1 - una dinàmica emocional oscil.lant, amb la qual els consumidors tendeixen a passar de la impotència culpabilitzadora associada a la contradicció, a l'autocomplaença quasi maníaca, associada a la proximitat de l'ideal a través del consum ecològic.

Aquesta lògica tindria unes implicacions ben clares sobre l'eficàcia simbòlica de la metamarca, en la mesura en què la reducció de la distància del jo dels consumidors i l'ideal rebaixaria la tensió psíquica, element motivacional clau des del model psicoanalític (Callejo, 1994: 101).

D: Bueno, això, que és molt difícil ser coherent amb tot, amb el tema compra, però sí, sí...

H: Bueno, potser no pots ser coherent del tot però bas..., sí que ho pots ser bastant. O sigui, clar, tot és impossible però, no sé... Jo conec gent de l'A. de Gràcia, per exemple, i vosaltres segur que també, que, que consumeix el $80-90 \%$ de tot el que consumeixen ho fan a través de la cooperativa m'han arribat a dir. Això és un nivell de coherència altíssim i està súper bé $[\ldots]$.

H: Sí, jo també... trobo que el que estem fent, bueno, està molt bé, o sigui... o sigui, es que és per estar molt content, muntar cooperatives, enterar-te d'aquestes coses, canviar els hàbits de consum...

D: Clar, clar...

$\mathrm{H}$ : Jo trobo que això és revolucionari, i..., jo m'ho miraria des d'una perspectiva molt positiva, no?, i dir que això és una passada! Arribar a la coherència... Pf! Això és impossible, això... (GD1)

$\mathrm{H}$ : Sí, sí, va ser una cosa per coherència, no una coherència al $100 \%$, perquè no crec que existeixi, però sí de dir: «Eh! Coherent! Me’n vaig a un lloc on pugui dir d'una manera lliure allò que penso, decidir pues eso, com una cooperativa: tothom igual», etc., etc... (EO1)

En un segon nivell de la sobredeterminació motivacional, aquesta dinàmica es veuria reforçada per la identificació amb el superjò socioambientalista, mitjançant el qual — seguint el sentit que Freud (1933) atorga al concepte-, aquests consumidors expressarien elements d'autoprohibició i renúncia, associats a les actituds afectives implicades en el consum ecològic. Des de la posició present, el consum ecològic no representaria només el fet d'adquirir productes amb uns atributs i uns valors determinats, sinó una actitud global de relacionar-se amb el consum, que es veuria emmarcada en un conflicte de metapreferències i que autors com Hirschman (1982: 82) ja han vinculat al superjò freudià. A banda de les expressions de renúncia a les "satisfaccions», a les «facilitats", o "al que és bo i pràctic", que, segons es reconeix, proporciona el mercat convencional ("D: No t'agrada, però reeduques, no...", GD1), el discurs és ple d'indicis que posen de manifest la dinàmica esmentada: l'ús d'atractors semàntics associats a la qüestió ecològica, com ara consciència, ètic, responsabilitat, entre altres, a manera d'imperatius normatius que cal complir en la pràctica del consum; l'ús de la segona persona del singular, manifest o latent, en diverses expressions clau, que indicaria la presència del «tu» en l'objectivació que els consumidors fan d'ells mateixos, amb la qual cosa es revelaria una rela- 
ció d'objecte pròpia del superjò, entre d'altes elements ${ }^{11}$. L'actitud ecològica es trobaria, d'aquesta manera, envoltada d'una dinàmica que enfrontaria el desig (consumista) amb la tendència superjoica que el coarta. En aquest cas, revestida ideològicament $\mathrm{amb}$ valors socioambientalistes. Una dinàmica viscuda quasi com un càstig pels consumidors: una "tasca molt dura", "per la qual has de batallar cada dia» (GD1), «amb moltes dificultats» (EO4), però la realització efectiva de la qual s'associa a una vivència positiva, digna d'aprovació i de reconeixement social i personal.

E: I què seria un ús racional, que has dit tu sobre l'ús racional?

D: Pues no tenir l'iPhone 4 quan toca potser. [...]

D: Jo crec que no hi pot haver ús racional. Si volguessis ser, o sigui..., jo, jo tinc un mòbil, jo tinc un ordinador. El que passa és que, per exemple, l'ordinador, no en tenim un per a cada persona a casa meva, no, o sigui que els compartim. Això està..., mínimament bé, no?, però jo trobo que realment, no n'hauríem de tenir. Però, bueno... [...].

D: Jo crec que lo que està bé és que fem consum crític, no?, abans de tot. Al final, acabarem anant al Zara o no, però sabem lo que hi ha, no?, que això és lo important. I això, no?, que tu vas a la cooperativa i, i consumeixes pròxim, ecològic, tal, clar... Pues podríem sudar i anar cada, un cop a la setmana consum, omplir el congelador i menjar mongetes triturades i seves congelades. Però no ho triem. Vull dir, dins del que potser seria lo més pràctic, i lo econòmicament més..., tothom li sortiria fantàstic, doncs seria allò, però dius, dins d'això, jo prefereixo construir una alternativa i clar, d'aquí i que llavors, com que estic en aquesta alternativa, doncs ja em torno [...] radical i integrista ecològic... És que, al final, és això, es que t’acabes tornant... Vull dir que si no acabes boig, vull dir... (GD1)

En aquest marc, la imatge del que és ecològic es configura en estreta i reivindicada associació amb els sintagmes de consum sostenible i responsable, la significació dels quals es desenvolupa considerant el mínim impacte ambiental possible, així com contemplant aspectes sociolaborals en l'àmbit de la producció ecològica, en una orientació que es creu més justa. En la mesura que s'usen com a anàlegs d'ecologic, se signifiquen com a valors diferencials clau per aquesta posició.

D’altra banda, és destacable que el discurs desenvolupa una jerarquia més o menys latent dels productes ecològics alimentaris a partir dels «atributs d'origen", aquells que mantenen relació amb la producció, la comercialització i la distribució que se'n fa. En els primers graons, hi hauria els productes que resten sotmesos a controls sobre l'ús de químics, pesticides, fertilitzants, etc., mentre que, als últims graons, els més preuats, s'ubicarien els que estan estretament lligats a qüestions socioambientals. Es postula que, en la producció ecològica, el medi ambient mai no ha d'estar supeditat als interessos econòmics,

11. "H: Una cosa que et fa ser és més conscient de les meves incoherències», «H: Un dia, vaig dir: "Vaig a ser ètic amb el tema roba..." (GD1) i «H: [...] perquè et demana o t'exigeix..." (EO1). 
perquè el que es fa en la producció esdevé fonamental per a la creació de les condicions d'un producte ecològic. D'aquí que, en aquest discurs, es tendeix a situar els atributs de la «proximitat» i la «temporalitat» entre els valors més rellevants en la configuració del que és ecològic, de manera que tots dos impliquen actituds de renúncia per ser efectius. Les cadenes associatives vinculen el primer a un valor favorable al medi, per la suposada reducció energètica implicada en el consum de productes procedents de zones pròximes al lloc on es creen. Però les associacions discursives es desenvolupen cap a una diversitat d'elements: ús reduït d'envasos; coneixement més ampli de les condicions de producció, reducció o evitació d'intermediaris; etc. La «temporalitat» es basaria en la renúncia a consumir productes que no siguin considerats propis «del temps», en una concepció que separa el que és natural del que és pròpiament humà. S'entendria que fer el que no és propi de la naturalesa pot ser perjudicial per a aquesta, perquè se sotmetria a un "esforç excessiu» (EO6). A nivell simbòlic, la temporalitat suposaria restablir la "comunió perduda» amb la natura, un reequilibri — emfatitzen els petits pagesos de l'EO4 i l'EO6 - basat en l'adaptació als seus ritmes i cicles, amb efectes beneficiosos per a l'ésser humà. L'obertura de l'atractor semàntic de la temporalitat ens desplaça cap al vector de la salut.

Desenvolupat en aquesta posició com a element secundari, el que és ecològic entronca amb el vector de la salut en el context d'una imatge negativa dels productes convencionals. Aquí la posició mostra dos nuclis discursius relativament diferenciats. Des de la concepció negativa dels productes convencionals, el primer nucli desenvolupa una actitud de desconfiança, especialment en referència als efectes sobre la salut que podrien exercir, a llarg termini, els sobreafegits químics que es creu que inunden bona part dels productes convencionals, particularment els alimentaris. Projecció futura del risc que reprodueix, com afirma Callejo (2010), el model del risc típic de la modernitat, i que aquí podem associar també a la condició de joves adults d'aquests consumidors, molt més avesats a controlar els esdeveniments propers i a situar l'horitzó en el temps futur, segons Lewis i Weigert (1992: 97). Per contra, el que és ecològic apareixeria com quelcom capaç de reduir aquesta incertesa, en la mesura que aconsegueix encarnar els valors simbòlics de la «seguretat», la «confiança» i la imatge de productes «descontaminats». El segon nucli, en canvi, es manté més confiat amb els mecanismes de control institucional dels productes i rebutja explícitament qualsevol projecció «excessiva» de temors sobre els productes alimentaris convencionals.

Finalment, el discurs de la posició revelaria un procés de diferenciació no ostentosa com a lògica motivacional al consum, amb aquells grups socials que es conceben més allunyats ideològicament, inclús a l'interior mateix del segment de consumidors ecològics. No representaria tant una estratègia ascendent de mobilitat social i simbòlica, com de distanciament respecte a uns altres col-lectius titllats d' «alienats», d' «ignorants» i d' «incapaços d'adonar-se de les problemàtiques socioambientals que preocupen aquests consumidors i d'entendre-les» (GD1, EO1, EO4). Si bé el distanciament s'ha tendit a negar en el nivell manifest del discurs, la mateixa reflexió sobre l'actitud diferenciadora ha posat de manifest l'existència d'aital orientació, que, en el desenvolupament discursiu més o menys 
latent, ha quedat paradoxalment reforçada amb les referències als altres a partir de fronteres sociosimbòliques (identitats, pràctiques de consum, etc.) que delaten la divisió entre ells i nosaltres. El consum ecològic es posa, així, al servei del reforç i del distanciament entre identitats col-lectives.

D: La gent que està lluny, si et veu així com molt ficat a la contra de... Estoy aquí con las cosas clarísimas...

$\mathrm{H}$ : Generes molta distància...

D: Rebuig... [...]

D: A veure, no es que hi hagin les dues categories, però una persona que només consumeix ecològic i se'n va al Veritas, per mi és diferent de mi... (GD1)

\subsection{El consum ecològic entre temors i fantasies de confiança: posició motivacional de la inseguretat defensiva}

Sorgida del discurs hegemònic de la fracció majoritària del GD2, així com de l'EO5 i l'EO7, representaria la concepció del consum ecològic més institucionalitzada i promoguda en els darrers anys pel mercat, en un contrast ben clar amb l'anterior. Aquesta posició orienta el discurs sobre el consum ecològic exclusivament en base al vector de la salut, d'aquí que el seu desenvolupament s'hagi configurat a l'entorn de les problemàtiques implicades en la denominada «modernitat alimentària» (Fischler, 1990). Les transformacions que han acompanyat la industrialització de l'alimentació, i especialment les conseqüències que se'n perceben, han constituït l'espai en què el discurs ubica i identifica els processos i les fonts de perill i de risc. L'abstracció del cicle de producció i consum, amb la pèrdua de contacte i de referents sobre la producció alimentària, provocarien, en aquests consumidors, un profund estat d'ansietat projectat sobre els processos de producció, conservació i manipulació dels aliments. Aquestes representacions fan emergir, ja des dels primers moments de les dinàmiques, una actitud bàsica d'inseguretat i de desconfiança davant dels productes convencionals. D'aquesta manera, el consum ecològic ha tendit a ubicar-se en un espai simbòlic privat i personal, en una projecció individualitzada d'aquest, orientat únicament a rebaixar les tensions personals derivades d'un context marcat per la inseguretat davant el mercat de productes convencionals. Així, l'estil discursiu ha mostrat un clima emocional ple de dubtes i d'ansietats respecte als temes plantejats en la discussió i en les entrevistes. Les representacions i la presa de consciència d'aquests consumidors sobre el fet que la realitat externa del consum i l'alimentació és viscuda com a amenaçant, així com la necessitat de fer-hi front, s'ha associat — seguint el plantejament de Melanie Klein ${ }^{12}$ — al desenvolupament d'una

12. Ens situem en les hipòtesis referides al desenvolupament infantil de la psicoanalista Melanie Klein, segons les quals les posicions en què s'estructura la psique són una part «normal» en el desenvolupament humà i tendeixen a reproduir-se en determinats moments durant la vida adulta. En el cas que ens ocupa, això succeeix davant d'un context percebut com a amenaçant. 
posició paranoide que se situaria en la gènesi de l'actitud d'inseguretat esmentada. El discurs ha desenvolupat, de forma maniquea, una imatge denigrant del mercat de productes convencionals i un discurs idealitzant referit al que és ecològic, molt particularment en referència als productes alimentaris.

L'elaboració discursiva orientada a la denigració dels productes convencionals s'ha configurat per dos processos més o menys diferenciats. Primer, una seqüència basada en el «desconeixement, la projecció, l'ansietat i la desconfiança», que situa, a l'origen de la desconfiança i l'ansietat, una "sensació» (EO5) de desconeixement expressada pels consumidors sobre els processos de producció i manipulació dels productes convencionals. El discurs, això no obstant, mostra contradiccions, en desplaçar-se del desconeixement al supòsit acceptat en el consens discursiu sobre l'extensió de l'ús de químics, transgènics, hormones, etc. en la producció alimentària. Es configura, així, el tòpic de la «contaminació» dels productes convencionals. El desconeixement, més que no pas la incertesa, tendeix a generar l'ansietat sentida davant de la suposada falta de control sobre els processos mencionats. És paradoxal, a més, que, si tenim en compte que el desconeixement constitueix el punt de partida d'aquesta lògica, el fet de disposar de més informació no sempre neutralitza els temors, sinó que pot multiplicar-los fins a convertir-los en insuportables: «D: Tinc el típic llibret de lo dolents que són els productes de la vida quotidiana [...]. $\mathrm{Ni}$ me'l penso llegir, és per agafar manies a tot» (EO5). En aquest sentit, han emergit, en el discurs, respostes emocionals associades a la por, articulades en fantasmes preconscients, com ara el de l'«engany»: «D: Está camuflao con una $\mathrm{E}$, con estos E no se qué...» (GD2); o el de la «manipulació»: «D: Cuando ves un producto que es tan barato [...], ¿¡Qué lleva esto!? ¡Es increíble! ¿iQué le ponen!?» (GD2).

D: La por, suposo, la por de totes les porqueries que hi fiquen. I sobretot la desconeixença, perquè no hi entenc gens no, sobre quins pesticides hi posen a cada lloc, no [...]. A vegades no saps realment què és el més sa... (EO5)

$\mathrm{H}:[\ldots]$ al tener un niño pequeño, no sabes si realmente la alimentación que les estás dando es realmente la que necesita, porque te pautan... (GD2)

En segon lloc, la seqüència no parteix de cap estímul previ i reprodueix una imatge més perillosa sobre el mercat de productes, sense necessitat de basar-se en cap element racionalitzador com ara el desconeixement. El discurs projecta directament l'omnipresència de perills i de productes nocius a tot arreu, en un clima quasi delirant. En un pla preconscient, els consumidors se situen com a «víctimes» d'una modernitat del consum persecutòria que no poden controlar, amb efectes perniciosos per a la pròpia salut ${ }^{13}$. Així ho mostra el temor als efec-

13. A banda de les citacions del text, mostrem algun altre fragment significatiu de les converses mantingudes:

$\mathrm{H}:[\ldots]$ També és perjudicial veure la tele a dos metros [...], una tele de quaranta i pico pulgades que també és perjudicial.

E: Tu la tens de quaranta i pico...? 
tes de determinats productes, tecnològics i alimentaris, sovint assenyalats per la seva «nocivitat» i perquè són causes — creuen- de malalties potencials. El procés d'incorporació, tal com havia assenyalat Fischler (1990: 65), tendeix a constituir-se com el més ansiós i problemàtic. Aquest evoca distintes vegades el fantasma kleinià de la incorporació de «l'objecte dolent», expressat en el discurs en l'ansietat persistent per la ingesta o la introducció d'elements perjudicials per a la salut per altres vies (cremes, ones, etc. $)^{14}$. Com apunta Segal (1981: 31): «La ansiedad predominante en la posición esquizo-paranoide es que el objeto u objetos persecutorios se introduzcan en el yo" per aniquilar-lo. D’aquí que el conflicte afectiu tingui com a rerefons la pròpia "contaminación», «intoxicación», la «enfermedad» i la «muerte» (GD2).

$\mathrm{D}:[\ldots]$ cada dia hi ha gent més malalta, més intoxicada, amb més fibromiàlgies, històries d'aquestes, i és molt la ingesta [...].

$\mathrm{D}$ : Asusta un poco y todo, eh, porque empiezas que si el Wi-Fi, que si el [...] de qué está hecho, todo lo que me rodea, que si el microondas, que si en el pueblo se utiliza... Pf?

H: Sí...

D: [...] y así, así y hay veces que dices: «Bueno, mejor no lo pienso...», porque te pones mala..., eh.

D: Sí, sí, sí... Al final, ya es un poco paranoico...

H: Sí, es que la gente en general hace eso, por eso no hay mucha... A lo mejor, no sabe...

D: Hombre y hay mucha gente que a lo mejor le hablas de ecología y, y le suena a chino, eh, como si vinieras de otra galaxia, eh... No tienen conciencia ninguna...

D: Voy por la calle y voy mirando las antenas...

D: Es que estamos dentro de un mundo tan envenenado que, realmente..., muchas veces he pensao "me da igual, si me voy a morir igual...». O sea que... (GD2)

Aquesta concepció planteja un estat d'alerta permanent entre els consumidors, en el qual es fa palesa la problemàtica sobre "què podem menjar», que el mateix Fischler (1990) ja atribueix al comensal contemporani. En aquesta posició, la problemàtica es redueix a la insistència a desitjar un consum saludable i una alimentació "més sana» (GD2). Desig bàsic i pràcticament institucionalitzat a les societats actuals, que el discurs mostra amb

H: No, la tinc de trenta i poques i sempre torta, una mica cap a un costat. I sempre porto...

E: Ulleres?

$\mathrm{H}$ : Ah, avui no el porto! No, un protector de freqüiencies.

E: Ah, per?

H: Tot ${ }_{2}$ els fluorescents, els bueno, els... [...]. Això ja és estudiar una mica més [...]. No el porto però aquí a la cartera porto una targeta que també és protectora... Seria el rotllo d'aquell tipus de polseretes però en plan serio. (EO7)

14. Algunes expressions simbòliques que il.lustren el conflicte per la incorporació de «l'objecte dolent» són les següents: «els tens a dintre nostre», «ens fiquem dintre del cos», «merda em menjo i si no respirant», «ficar-te coses químiques al cos». 
l'ideologema del «culte a la vida saludable». La realització d'aquest desig és projecta, precisament, en el consum ecològic, quan encarna el valor del que és saludable i situa la imatge dels productes ecològics en el camp del menjar, com a «aliments saludables». Aquesta configuració es realitza en un procés d'idealització que - en el sentit kleinià de la noció- constitueix una defensa per als consumidors contra les pròpies ansietats i temors, per la qual cosa els productes ecològics es conceben com uns autèntics elements compensadors davant de l'assetjament alimentari percebut; d'aquí sorgeix, en part, la seva eficàcia simbòlica.

La imatge simbòlica del producte ecològic es desenvolupa a partir de valors amb ressonància afectiva, com ara la «seguretat", la "tranquil-litat" o la "confiança», amb la qual cosa es crea un context significatiu oral, en el sentit psicoanalític del terme (en aquest context social i discursiu, sense els elements de la voracitat i el consum en quantitat). El que és ecològic es converteix, així, en un receptacle de desigs i fantasies orals d'incorporació de formes simbòliques de «l'objecte bo».

Aquest espai imaginari del consum saludable ha qualificat els productes ecològics de «sans», «veritables», "segurs». Amb el que és ecològic, especialment les mares de família entrevistades, restableixen la confiança en l'alimentació, associant-la a un benestar reconfortant, gratificant, que tendeix a desconflictivitzar la ingesta, deixant a certa distància qualsevol tipus de malestar, com fan les relacions amb preponderància oral. Les associacions discursives han arribat a evocar la lactància materna, en base a la qual els productes ecològics alimentaris es proposarien com a continuïtat simbòlica de la citada pràctica. Les fantasies d'apropiació oral han emergit també en les referències a les immenses capacitats nutritives i vitamíniques dels productes ecològics, adreçades a l'assimilació en un mateix. Procés que, de forma concreta, es desenvolupa a partir de l'imaginema del caràcter «preventiu» de l'alimentació ecològica, i la capacitat d'endarrerir determinades malalties, així com multiplicar les defenses del cos. Apareix també l'imaginema de les capacitats "curatives", que situa el consum ecològic en el marc del procés de medicalització de l'alimentació (Gracia Arnaiz, 2007). Finalment, s'observa una línia simbòlica nostàlgica, segons la qual, els productes ecològics, especialment els alimentaris, s'associen a una certa enyorança del món antic, d'abans, rural — personalitzat en la figura dels avis-, en un context d'idealització d'un passat en què semblava que no existien perills ni conflictes amb els processos alimentaris. Més que tornar al passat, aquest es vol fer present.

D: Tranquil-litat total i absoluta, tranquil.litat total i absoluta. I, sincerament, vull dir, allò que t'estàs menjant una poma i..., oa! que bé m'estan sentant, saps?... Una sensació de sa, que és una cosa sana allò que t'estàs menjant, una cosa de veritat, saps? Vull dir, et menges una poma i és una poma! no és res més que una poma, saps?, o...

E: I bueno, alguna cosa més...

D: És que em dóna això [...] de tranquil.litat i molt... I sensació d'això, de sa, que estàs menjant algo sa. (EO5) 
D: Que la gente acceda a esas informaciones, y que tenga conciencia que realmente lo que se mete... es la salud, de, de, jsu vida! Y claro, yo, en este sentido, compro en Bio Space, y compro en Veritas y compro en algún payés $[\ldots]$.

D: Los naranjos, por ejemplo, tienen el $30 \%$ más de vitamina $\mathrm{C}$ que una... De producciones de esta masiva, no... O sea que...

$\mathrm{H}$ : Agafes una poma ecològica, i vist des d'aquest altre punt de vista, efectivament, perquè surt com surt, i no importa!, perquè està en allà, però la quantitat d'aliment que hi ha en aquella fruita, és molt diferent de l'altra... (GD2)

Des d'una perspectiva socioestructural, destaquem una doble lògica de diferenciació social i simbòlica que es fa patent en els discursos. La primera, respecte als no consumidors ecològics, que s'afirma com a estratègia ascendent, i per la qual els no consumidors ecològics — fonamentalment els sectors popularsserien aquells que no mostrarien interès pels canvis associats a l'alimentació, $\mathrm{i}$ especialment per les conseqüències que comporten ${ }^{15}$. La segona, es desenvoluparia a l'interior del segment del consum ecològic a partir de dues estratègies:

1) Diferenciació respecte d'aquells que no s'apropien «correctament» ni legítimament dels productes ecològics, amb la qual cosa es posen de manifest les diverses projeccions dels habitus en les valoracions i en les classificacions de les pràctiques de consum.

2) Diferenciació respecte als percebuts com a consumidors ecològics adinerats, sobre els quals es projecten algunes dosis d'hostilitat. En aquest darrer cas, lluny de l'emulació vebleniana, els consumidors es distancien respecte als sectors situats (almenys imaginàriament) al cim de l'estructura social ${ }^{16}$.

\subsection{El consum ecològic com a "deure»: posició motivacional de la responsabilitat individualista}

Sorgida del discurs predominant de la fracció minoritària del GD2, així com de l'EO2, l'EO3, l'EO8 i l'EO9, se situaria en un espai discursiu central respecte als anteriors. Es tracta d'un discurs que expressa més variabilitat en la concepció sobre el que és ecològic i més sobredeterminació motivacional. En el marc

15. D: [...] I això enganxa a la gent que no té criteri... Nosaltres tenim una edat, ja tenim una informació, ja pensem, però la immensa mass media..., no! [...].

$\mathrm{H}$ : Exacte! (GD2)

$\mathrm{H}$ : Vale, no, jo trobo que hi ha qui es mou com una ovella i creu tot el que li diuen, i que menja allò perquè li diuen que és bo [...]. Intentes sortir de lo que és la societat en si normal. (EO7)

16. Alguns exemples d'estratègies són els següents:

$\mathrm{H}$ : El que té el carro dels embotits envasats i tal, aquest està traslladant la compra que faria en un supermercat habitual a un supermercat ecològic. No està canviant aliments, està canviant de convencional a ecològic entre cometes. (GD2)

D: Las personas que están convencidas, que saben, pero, ¡qué va! [...] Hoy son ecológicos y mañana... A eso de tres días cambian a otro tipo de cosa...(GD2) 
del vector socioambiental, ha tendit a dibuixar, més o menys críticament, un context social, econòmic $\mathrm{i}$ ambiental marcat pels límits associats a cadascuna d'aquestes esferes. Es representa el final del model de societat tal com ara es coneix, si no s'hi introdueixen canvis que frenin el que s'entén, de manera més o menys latent, com a "desequilibris». La identificació de distintes problemàtiques, com ara el domini de les grans empreses, el consumisme excessiu i la desigualtat al món, a més de la cada vegada més propera — diuen els consumidors - crisi energètica amb la fi del petroli, s'articula amb la incapacitat d'imaginar i desenvolupar discursivament cap tipus de transformació social real i profunda. Incapacitat associada a la concepció del consum ecològic com la possibilitat (individual) de "fer alguna cosa» (GD2) davant les esmentades problemàtiques. Es realitza, així, una projecció social del consum ecològic a manera d'intervenció ciutadana, definida més en termes d'acció individual que no pas col-lectiva, tal com ho mostra la metàfora del vot apareguda al GD2: el consum ecològic, com passa en la participació electoral, seria un mecanisme d'intervenció socioambiental individualitzada, l'èxit de la qual dependria de la suma d'actes individuals de consum. D'aquesta manera, el consum ecològic es defineix com una pràctica individual, com una manera d'exercir la responsabilitat per part de cada un dels consumidors, per tal de fer front a les problemàtiques que més o menys preocupen, de manera que el consum, o inclús la compra, és l'inici i la fi de la intervenció.

L'estructura simbòlica de la imatge del consum ecològic la conforma un conjunt de valors i de creences fonamentades sobre perceptes morals revestits ideològicament de contingut socioambiental. Consumir ecològicament significaria, segons aquests consumidors, defensar el medi ambient, mantenir una actitud solidària o altruista amb els altres (pobres, petits pagesos, etc.), en una dinàmica motivacional que seguiria — en un primer nivell manifest - una orientació racional fonamentada en valors (Weber, 1922: 20, 21). El fet d'actuar així s'experimenta com la realització d'un «bé» («fer coses bones al món», EO3), o d'una «ajuda» per a determinats col-lectius desfavorits. La seva vivència subjectiva adquireix forma d'autocomplaença associada a la gratificació personal:

H: Jo diria que sí, en el sentit que et fa ser responsable, i si tu ets responsable $i$ tu et vols autoenganyar, tu et pots autoenganyar, evidentment, però, si més no, ja obre una porta, una porta a la responsabilitat. Des del meu punt de vista. (GD2)

D: [...] Després, i associada amb aquesta, viure en un món on tot sigui... tenir cura de la natura i dels nostres recursos... És una cosa que m’importa, o sigui, ser responsable en aquest sentit, doncs m'importa [...]

E: Lo fonamental seria lo del...

D: Sí, i aleshores s'ha despertat aquest sentiment de responsabilitat, no?, i de sentir-te a gust fent algo de responsable cara al planeta, no? Això dóna satisfacció. (EO3)

En un pla més latent de la dinàmica motivacional, el superjò socioambientalista s'evidencia en el discurs —en un nucli de la posició- novament a través 
de l'evocació de l'esforç i el sacrifici associats a la imatge i la pràctica del consum ecològic. Aquest es concep com «una feina», quelcom que «no surt gratis», però que, això no obstant, «es lo que toca, consciència a fer», que "costa molt, però poc a poc...» (GD2). També, en aquest nucli, es desenvolupa la dimensió latent de la "culpa", a la qual es pot atribuir un cert valor motivacional, en la mesura que el consum ecològic s'associa al «deure» $\mathrm{i}$, a la vegada, al compliment dels preceptes morals ${ }^{17}$. La pràctica del consum ecològic tindria com a correlat eludir la culpabilitat per no haver-lo complert, amb la qual cosa es requeriria una actitud disciplinada (Callejo, 1996: 81). S’observa, tanmateix, un nucli que es mostra més partidari de no desvincular el consum de les «facilitats» i les "comoditats» (EO9), rebutjant els components superjoics del primer.

Respecte als atributs de la imatge dels productes alimentaris ecològics, implicarien l'absència d'agressions a la «la Terra» o «el planeta», d'acord amb l'evocació dels tipus de producció ecològica; el nucli de petits pagesos posen un èmfasi especial en la necessitat d'establir una relació de "respecte» vers la Terra (EO2, EO8), i els atributs de la "proximitat» i la «temporalitat», encara que menys desenvolupats discursivament que a la primera posició, també apareixen com a valors fonamentals dels productes ecològics alimentaris, associats a significants com a «KM0» $\mathrm{o}$ «local», entre d'altres. En aquest discurs, hi apareix el transgènic més associat a la pobresa del Tercer Món que no pas als problemes de salut, amb la qual cosa s'afirma, sens dubte, com un contravalor ecològic, és a dir, esdevé allò que s'hi oposa absolutament.

El vector de la salut s'ha desenvolupat, mitjançant una clara coincidència amb la posició anterior, amb els processos de seguretat i d'inseguretat alimentària com a espai discursiu central. Al GD2, el nucli integrat a la present posició ha tendit a acceptar la concepció paranoide predominant, si bé ho ha fet amb una càrrega emocional més baixa, $\mathrm{i}$ amb una racionalització més gran dels perills i dels riscs associats amb els processos alimentaris. Un dels elements centrals de les actituds de desconfiança ha estat la representació de la contradicció que, segons aquests consumidors, viu la indústria alimentària. Es relata que aquesta té el benefici econòmic com a objectiu principal, valorat com a incompatible amb els criteris de qualitat i seguretat del menjar. El producte industrial, a més, se situa dins de l'espai semàntic del que és «manipulat», "químic» o "tòxic», quan el que es valora és l'ètica de la no-intervenció: el producte ecològic es valora pel seu caràcter míticament «natural» (Barbeta, 2014c). No podem deixar d'assenyalar, però, l'existència d'un nucli discursiu més proper a les posicions depressives (en sentit kleinià, per l'assumpció de les potencialitats «bones» $\mathrm{i}$ «dolentes» de tot producte), en el qual s'accepta l'ús d'elements químics en la producció, quan el mal de no utilitzar-los és més gran, encara que sempre cal fer-ho sota el control més estricte.

17. «D: Em costaria, perquè a vegades ho intento de dir: "Vinga, va! Compres d'això que no és ecològic, que et sortirà més barato i tal", i aleshores haig de fer un raonament: "No passa res, si estàs consumint una major part de productes ecològics, perquè en consumeixis algun que no ho són, no passa res [...]”" (EO3). 
H: Per exemple, parlant de les pomes, responent a la pregunta, clar, em... Una poma és un objecte que es ven... Pot servir per alimentar o pot servir simplement perquè és un objecte que s'ha de treure un profit. Evidentment, ha de ser maca, ha de ser llustrosa, ha de tenir un brillo, un color, un tamany... Això vist des del punt de vista, de, simplement, mercantil. I així és com funcionen les empreses... El que no diuen és que, per aconseguir aquest producte, hi ha 20 tractaments al darrere, fitosanitaris, 20 tractaments. Aquí, més, més fotut que a altres llocs, no? (GD2)

Observem dues línies simbòliques, més o menys diferenciades, de desenvolupament de la imatge del que és ecològic. Primera, la concepció del consum ecològic com una part essencial de determinats particularismes alimentaris (dietes, vegeterianisme, macrobiòtica, etc.), en els quals es projecten els habitus alimentaris propis de determinades fraccions de classe mitjana i mitjana-alta, amb la qual cosa se n'assenyalen les capacitats distintives, tal com mostren els treballs de Miller (2001) o Warde (1997). Aquí, la medicalització de l'alimentació i la diferenciació social es reforçarien mútuament. Així mateix, convé destacar l'articulació dels esmentats estils alimentaris amb un component anal associat — a nivell afectiu — amb les actituds de propensió a l'ordre, a la perseverança i a la fixació en els principis que impliquen aitals estils. En segon lloc, i en consonància amb altres posicions, el producte ecològic es configura com a «natural», dóna "tranquil.litat» $\mathrm{i}$ «seguretat», en una línia que expressa el desig oral projectat sobre la imatge de la metamarca, també associada a fantasies orals, segons les quals, als productes ecològics, "no les falta de nada», tindrien "vitamines, vitalidad» $\mathrm{i}$, en definitiva — s'imaginen_- "todas las propiedades» (GD2 i EO3) per ser ingerides pels consumidors i apropiades per a ells. Fins i tot en el discurs dels petits agricultors, hi ha emergit l'imaginema de la capacitat «curativa» dels productes ecològics, amb la qual cosa caracteritzen la seva activitat laboral com un projecte «agrosanitari» (EO8).

H: [...] El producte ecològic, quant a gust... Aviam, en el fons, el gust jo crec que són les vitamines que no té l'altre, bàsicament és això. Vull dir, a l'altre està menjant fibra, amb un enciam estàs menjant fibra, estàs menjant cel.lulosa, però en l'altre cantó, en l'altre cantó, hi menges la fibra, la cel-lulosa, però, a més a més, les vitamines i, i els, els, tot diguéssim, els elements que hi puguin anar que en l'altre no tenen. Per què? Doncs perquè s'ha forçat el rec, perquè se li han posat hormones o perquè..., etc, etc., se li ha posat un adob sintètic que ve del, del petroli, i està depurat... I, és clar, el petroli, quin gust té? (EO8)

Des d'aquesta posició, també es desenvolupa una estratègia de diferenciació ascendent respecte als no consumidors ecològics, a qui es considera una majoria social passiva, ignorant i cega a la rellevància (ideològica) de les relacions entre consum, alimentació i medi ambient, en línia amb el discurs anterior («deu ser per desconeixement...», EO9). D'altra banda, es marca un cert distanciament amb els consumidors ecològics considerats menys "convençuts», els que, 
il.legítimament, consumeixen "por la pose», «por las apariencias» (GD2). El consum ecològic s'afirma i es desenvolupa com un mitjà per marcar la diferenciació social amb les fraccions de classe amb elevats capitals cultural i simbòlic com a grups de referència en l'estructura social.

H: Jo diria que estem parlant de la majoria de la població, no? Jo diria que és una majoria abrumadora..., no? I, dins d'aquesta majoria abrumadora, deu haver-hi una part important que, senzillament, va a la seva rutina, i la seva rutina no passa per l'ecologia, perquè senzillament no, no, no hi ha cap pregunta... Senzillament... (GD2)

\section{Conclusions}

La perspectiva sociomotivacional desenvolupada en aquest treball s'ha mostrat fecunda en l'anàlisi del consum ecològic. Des d'una proposta empírica d'orientació qualitativa, ens ha permès configurar l'estructura motivacional del consum ecològic entre els perfils majoritaris dels consumidors catalans. El model estructural i genètic configurat diferencia tres posicions motivacionals bàsiques (socioambientalista comunitària, en relació amb la inseguretat defensiva i amb la responsabilitat individualista), en les quals l'eficàcia simbòlica de la imatge del producte ecològic ha mobilitzat elements i lògiques psicosocials específiques, que desemboquen en processos motivacionals més o menys diferenciats.

L'anàlisi del discurs ens ha informat de la importància del vector simbòlic de la salut en totes les posicions discursives, com a component motivacional favorable al consum ecològic. Coincidim, així, encara que de forma parcial, amb les investigacions que han relacionat la demanda de productes ecològics amb les preocupacions creixents dels consumidors per la seguretat alimentària, com també pel desig de mantenir una alimentació més sana (Lockie et al., 2002; Gracia i Magistris, 2008; Lea i Worsley, 2005). Tanmateix, de l'anàlisi, en deriven algunes cauteles a l'hora d'interpretar aquestes qüestions i d'altres, com ara la valoració de les característiques organolèptiques dels productes (Lea i Worsley, 2005), com a lògiques «hedonistes» o «lúdiques» de consum. En contra de la manera com acostuma a caracteritzar-se el model de consumidor (in)satisfet de la societat de consum, el consum ecològic es desenvoluparia, més aviat, des d'uns principis defensius i reactius; principis inscrits en una lògica motivacional més compensatòria que no pas de gaudi, expressada en un clima de preocupació i d'inquietud permanent per part dels consumidors. Associades a les preocupacions per la salut, les imatges i les representacions negatives sobre els contextos alimentaris que caracteritzen avui -almenys en part- les nostres societats de consum, tenen un pes fonamental en la gènesi dels processos de consum ecològic. Ja hem vist com les representacions sobre la indústria alimentària i les suposades conseqüències que comporten constituïen un espai discursiu per identificar fonts de risc i de perill, davant de les quals el consum ecològic es proposaria com a sortida. Contrarestant els efectes suposadament 
nocius dels productes convencionals, especialment els alimentaris, consumir de manera ecològica s'ha projectat constantment en els discursos com una forma simbòlica — qui sap si també factica i real? - de consumir «bona salut» $\mathrm{i}$ «seguretat», en tot allò que es refereix a les pràctiques d'ingesta. D'aquesta manera, en determinats sectors de consumidors, el consum ecològic es proposaria com un valor «segur» que tendeix a contrarestar la cobertura i el control insuficients dels riscs des de l'àmbit institucional (Beck, 2006). I així, en la mesura que la seva imatge depèn en bona part de les projeccions afectives i valoratives dels seus consumidors, es convertiria en una opció privada, personal i (majoritàriament) mercantil de fer front als perills, a les desconfiances $i$ als desafiaments que els mateixos consumidors valoren com a creixents.

D'altra banda, també hem vist que, en algunes orientacions discursives, el consum ecològic s'ha concebut com una eina per a la transformació «ecosocial» de la societat o, des d'una visió més moderada, com una manera de complir determinats valors i preceptes morals, associats a la defensa del medi ambient, en un sentit relativament ampli (menys despesa energètica, ús racional d'envasos, suport a l'agricultura local i sostenible, etc.). En una línia parcialment semblant, s'han desenvolupat investigacions com les de Lea i Worsley (2005) i Gracia i Magistris (2008), estrictament vinculades a qüestions de consum. D'altra banda, les posicions motivacionals analitzades revelen que el consum, i, tal vegada, el consum ecològic potser n'és un model paradigmàtic, es reconverteix en una esfera de ciutadania, de manera que part del consum ecològic també esdevé una forma de mobilització o d'acció col-lectiva, mitjançant la qual s'expressa la seva identitat (parcial) com a moviment social. Aquesta dimensió del consum ecològic podria relacionar-se, des d'altres àmbits d'estudi, amb el plantejament d'estils nous de governança i regulació ambiental, atès que les xarxes de consum ecològic s'orienten, almenys parcialment, per l'ambició de fer front a les crisis i a les problemàtiques ambientals, a partir de models deliberatius i més legítims d'intervenció política (Fiorini, 2006). En aquest sentit apunten els treballs de la sociologia rural inscrits en el desenvolupament de l'agroecologia (Sevilla Guzmán, 2006) o els que posen l'èmfasi en el desplaçament del consum cap a l'exercici dels drets de ciutadania (Rief, 2008). Tanmateix, no falten crítiques a aquest tipus de concepcions normatives, ja sigui per la manca d'evidències de la seva eficàcia, pels desequilibris entre el poder dels actors implicats o per la inadequació dels plantejaments subjacents (Cohen, 2013).

També és cert que el desenvolupament del vector socioambiental no s'ha produït en la totalitat de posicions motivacionals identificades, la qual cosa podria indicar que, al contrari que el vector de la salut, tan sols és present en alguns sectors socials de consumidors. Així mateix, entre aquests sectors socials, existeixen, com hem vist amb les posicions socioambientalista comunitària i de la responsabilitat individualista, diferències importants en la concepció significativa del consum ecològic. Diferències que, entre altres impactes, solen traduir-se en pràctiques i en canals de consum distints, amb conseqüències comercials evidents en el camp dels productes ecològics (Tendero, 2011), com 
també amb implicacions ideologicopràctiques oposades. Suggerim, addicionalment, que els límits en la consolidació de les orientacions motivacionals socioambientals (i, en part, la plasmació que se'n realitza en actes de compra) estan associats a la lògica contradictòria i conflictiva viscuda (més o menys conscientment) pels consumidors que suposen els components de la renúncia $\mathrm{i}$ el deure. Mentre siguin aquestes les lògiques motivacionals associades al vector socioambiental, possiblement importants sectors de la societat no tindran prou raons per orientar-se cap al consum ecològic, almenys pel que es refereix a l'aspecte socioambiental.

Per acabar, si el consum ecològic il.lumina un model nou de consumidor com el que dibuixen Rochefort (1997) o Alonso (2005), assentat en els valors de la qualitat, la reflexivitat o la responsabilitat, així com també en la preocupació per la seguretat i les capacitats d'individualització que ofereix l'àmbit del consum, podríem dir que mostra, al mateix temps, els seus propis límits com a model de consum «alternatiu» (Fresneda, 1998). Hem vist que es tracta d'un consum que expressa uns tipus específics de desigualtat social i de dualització cultural, en la mesura en què les tendències i els valors o les normes que hi estan associats (com ara la qualitat, l'autocontrol, la importància del coneixement, etc.) serien propis de sectors socials amb capitals culturals, simbòlics i econòmics elevats i estarien traçats per ells mateixos. És per això que, en la projecció en l'estructura social, el consum ecològic apareix en els discursos com un mitjà per a la diferenciació social i simbòlica entre consumidors ecològics, i entre aquests i no consumidors ecològics. Per tant, no deixa de constituir, com ja ha assenyalat Miller (2001) o Horton (2003), un element utilitzat pels grups i les classes socials per afirmar-se i distingir-se en les lluites simbòliques i ideològiques a través del consum.

\section{Referències bibliogràfiques}

Alonso, Luis Enrique (1998). La mirada cualitativa en sociología. Madrid: Fundamentos.

- (2005). La era del consumo. Madrid: Siglo XXI.

Barbeta Viñas, Marc (2014a). «De los vínculos en el consumo al consumo en los vínculos: Análisis de las formas de sociabilidad en las prácticas de consumo ecológico». Revista Española de Sociología, 22, 67-95.

- (2014b). «Análisis motivacional del consumo: Recontextualización y propuesta de ampliación». Investigación y Marketing, 123, 44-50.

- (2014c). «La mitología de lo ecológico: Una reflexión socio-semiológica». Distribución y Consumo, 40, 36-43.

BЕCK, Ulrich (2006). La sociedad del riesgo mundial: En busca de la seguridad perdida. Barcelona: Paidós, 2007.

Borràs, Vicent (1998). El consumo, un análisis sociológico: La estructuración del consumo y los grupos sociales en la Región Metropolitana de Barcelona. Barcelona: Cedecs.

Bourdieu, Pierre (1979). La distinción: Criterios y bases sociales del gusto. Madrid: Taurus, 1988.

- (1980). El sentido práctico. Madrid: Taurus, 1991. 
Callejo, Javier (1994). «Modelos de comportamiento del consumidor: A propósito de la motivación». Política y Sociedad, 16, 93-110.

- (1995). «Elementos para una teoría sociológica del consumo». Papers: Revista de Sociologia, 47, 75-96.

- (1996). «El reciclaje de la ecología en el consumo». Estudios sobre Consumo, 39, 75-89.

- (2010). «La confiança en l'alimentació dins les societats modernes». Papers: Revista de Sociologia, 95 (2), 483-504.

Castro Nogueira, Luis Alfonso i Castro Nogueira, Miguel Ángel (2001). «Cuestiones de metodología cualitativa». Empiria: Revista de Metodología de Ciencias Sociales, 4, 165-192.

Centre d'Estudis D’Opinió (2009, 2010, 2012). Baròmetre de percepció i consum dels aliments ecològics. Barcelona: Generalitat de Catalunya [en línia].

<http://pae.gencat.cat/ca/estadistiques-observatori-pae/documents-estudis/ consum/\#FW_bloc_f99595cd-c4a3-11e3-8540-000c296817af_> [Consulta: setembre 2013].

Chaney, David (1996). Estilos de vida. Madrid: Talasa, 2003.

Cohen, Miriam, A. (2013). «Democracia deliberativa y gobernanza ambiental: ¿Conceptos transversales de una nueva democracia ecológica?». Sociológica, 28 (80), 73-122.

Conde, Fernando (2009). Análisis sociológico del sistema de discursos. Madrid: Centro de Investigaciones Sociológicas.

Federació de Cooperatives de Consumidors i Usuaris de Catalunya (2010). Els grups i les cooperatives de consum ecològic a Catalunya [en línia].

$<$ http://xarxanet.org/sites/default/files/Diagnosi_grups_de_consum_Catalunya. pdf> [Consulta: setembre 2013].

Fiorini, Daniel (2006). The New Environmental Regulation. Cambridge: The MIT Press.

Fischler, Claude (1990). El (h)omnivoro: El gusto, la cocina y el cuerpo. Barcelona: Anagrama, 1995.

Fresneda, Carlos (1998). La vida simple: De los excesos de la sociedad de consumo a la busca de nuevos estilos de vida. Barcelona: Planeta.

Freud, Sigmund (1905). "Tres ensayos de teoría sexual». Obras Completas. Buenos Aires: Amorrortu, 1986.

— (1933). «Nuevas conferencias de introducción al psicoanálisis». Obras Completas. Buenos Aires: Amorrortu, 1986.

Gerth, Hans i Wright Mills, Charles (1984). Carácter y estructura social: La psicología de las instituciones sociales. Barcelona: Paidós.

Gracia, Azucena i Magistris, Tiziana de (2008). "The demand for organic foods in the South of Italy: A discrete choice model». Food Policy, 33 (5), 386-396.

Gracia Arnaiz, Mabel (2007). «Comer bien, comer mal: La medicalización del comportamiento alimentario». Revista de Salud Pública de México, 49 (3), 236-242.

Grignon, Claude i Passeron, Jean-Claude (1992). Lo culto y lo popular: Miserabilismo y populismo en sociología y en literatura. Madrid: La Piqueta.

HebDidge, David (1979). Subculturas: El significado del estilo. Barcelona: Paidós, 2004.

Hirschmann, Albert O. (1982). Interés privado y acción pública. Mèxic: Fondo de Cultura Económica, 1986.

Horton, Dave (2003). "Green Distinctions: The Performance of Identity among Environmental Activists». The Sociological Review [en línia], 51 (2), 63-77. <http://dx.doi.org/10.1111/j.1467-954x.2004.00451.x>. 
IвÁÑEZ, Jesús (1969). «Investigación profunda y motivación». Cuaderno 2: Marketing para publicitarios, INP, 81-102.

- (1979). Más allá de la sociología: El grupo de discusión: teoría y crítica. Madrid. Siglo XXI.

IzQuierdo, María Jesús (1996). «El vínculo social: Una lectura sociológica de Freud». Papers: Revista de Sociologia, 50, 165-207.

Klein, Melanie (1946). "Notas sobre algunos mecanismos esquizoides». A: KLein, Melanie. Desarrollos en psicoanálisis. Buenos Aires: Hormé, 1967.

Knodel, John (1993). "The design and Analysis of Focus Group Studies». A: MorGAN, David. L. (ed.). Succesful focus groups: Advancing the state of the art. Newbury Park: Sage.

LeA, Emma i Worsley, Tony (2005). «Australian's organic food beliefs, demographics and values». British Food Journal [en línia], 107 (11), 855-869. <http://dx.doi.org/10.1108/00070700510629797>.

Lewis, David J. i Weigert, Andrew J. (1992). «Estructura y significado del tiempo social». A: Ramos Torre, Ramón (comp.). Tiempo y sociedad. Madrid: CISSiglo XXI.

Lockie, Steward; Lyons, Kristen; Lawrence, Geoffry i Mummery, Kerry (2002). "Eating "green": Motivations behind organic food consumption in Australia». Sociologia Ruralis [en línia], 42 (1), 23-40. <http://dx.doi.org/10.1111/1467-9523.00200>.

Lorenzer, Alfred (1970). Crítica del concepto psicoanalítico de símbolo. Buenos Aires: Amorrortu, 1976.

Lucas, Ángel de (1988). "Publicidad e ideología». A: Anunciar o la utilidad de la belleza. Madrid: Contrapunto, 21-26.

Malrieu, Phillippe (1971). La constricción de lo imaginario. Madrid: Guadarrama.

Marinas, José Miguel (2012). Investigar la cultura del consumo. Madrid: Síntesis.

Miller, Daniel (1987). Material Culture and Mass Consumption. Cambridge: Basil Blackwell.

- (2001). The Dialectics of Shopping. Chicago: University of Chicago Press.

OrTí, Alfonso (1979). «Motivaciones turísticas europeas e imagen turística de España 1977: Un enfoque cualitativo». Revista de Estudios Turísticos, 63-64 (3-4), 5-123.

- (1986). «La apertura del enfoque cualitativo o estructural: La entrevista abierta semidirectiva y la discusión de grupo». A: García Ferrando, Manuel; Ibáñez, Jesús i Alvira, Francisco (comps.). El análisis de la realidad social: Métodos y técnicas de investigación. Madrid: Alianza.

- (1987). «El proceso de investigación social como proceso de comunicación. (Las bases de la creatividad de la oferta: proceso motivacional de la conducta del consumidor en el mercado neocapitalista)». Seminari de CIMOP La creatividad condicionada. Madrid (no publicat).

- (1994). «La estrategia de la oferta en la sociedad neocapitalista de consumo: Génesis y praxis de la investigación motivacional de la demanda». Politica y Sociedad, $16,37-92$.

- (1998). «Libido». A: Giner, Salvador; Lamo de Espinosa, Emilio i Torres, Cristóbal. Diccionario de Sociología. Madrid: Alianza.

Ricoeur, Paul (1975). Hermenéutica y estructuralismo. Buenos Aires: Megápolis.

RiechmanN, Jorge (1994). Redes que dan libertad: Introducción a los nuevos movimientos sociales. Barcelona: Paidós. 
Rief, Silvia (2008). "Outlines of a Critical Sociology of Consumption: Beyon Moralism and Celebration». Sociology Compass [en línia], 2 (2), 560-576. <http://dx.doi.org/ 10.1111/j.1751-9020.2007.00085.x>.

RochefORT, Robert (1997). Le consommateur entrepreneur. París: Odile Jacob.

SEgAL, Hanna (1981). Introducción a la obra de Melanie Klein. Barcelona: Paidós.

Sevilla Guzmán, Eduardo (2006). «La agroecología como una alternativa de sustentabilidad rural». A: Morales, Jaime i Rocha, Jorge E. (eds.). Sustentabilidad rural y desarrollo local. Mèxic: ITESO.

Simmel, Georg (1911). Sobre la aventura: Ensayos filosóficos. Barcelona: Península, 1988.

Slater, Don (1997). Consumer Culture and Modernity. Cambridge: Polity Press.

Tendero, Guillem (2011). «Escenaris i tendències en el consum de productes ecològics». A: Morales, Soledad (eds.). Som el que consumim?: Escenaris i tendències en el consum de productes ecològics. Barcelona: Editorial UOC.

Therborn, Goran (1980). La ideología del poder y el poder de la ideología. Madrid: Siglo XXI, 1987.

Warde, Alaine (1997). Consumption, Food and Taste: Culinary antinomies and commodity culture. Londres: Sage.

Weber, Max (1922). Economía y sociedad: Esbozo de una sociología comprensiva. Mèxic: Fondo de Cultura Económica, 1964. 